\title{
Paraspinal Muscle Sparing Versus Percutaneous Screw Fixation: A Comparative Enzyme Study of Tissue Injury during the Treatment of L4-L5 Spondylolisthesis
}

\author{
Dong Am Park, Seok Won Kim, Sung Myung Lee, Chang II Ju, \\ Chong Gue Kim, Suk Jung Jang \\ Department of Neurosurgery, College of Medicine, Chosun University, Gwangju, Republic of Korea
}

\begin{abstract}
Objective: Screw fixation via the paraspinal muscle sparing approach and by percutaneous screw fixation are known to diminish the risk of complications, such as, iatrogenic muscle injury as compared with the conventional midline approach. The purpose of this study was to evaluate tissue injury markers after these less traumatic screw fixation techniques for the treatment of L4-L5 spondylolisthesis.

Methods: Twenty-two patients scheduled for posterior lumbar interbody fusion (PLIF) at the L4-L5 segment for spondylolisthesis were prospectively studied. Patients were divided into two groups by screw fixation technique (Group I: paraspinal muscle sparing approach and Group II: percutaneous screw fixation). Levels of serum enzymes representing muscle injury (CK-MM and Troponin C type 2 fast), pro-inflammatory cytokine (IL-8), and anti-inflammatory cytokine (IL-1ra) were analyzed using ELISA techniques on the day of the surgery and 1,3 , and 7 days after the surgery.

Results: Serum CK-MM, Troponic C type 2 fast (TNNC2), and IL-1ra levels were significantly elevated in Group I on postoperative day 1 and 3 , and returned to preoperative levels on postoperative day 7 . No significant intergroup difference was found between IL-8 levels despite higher concentrations in Group I on postoperative day 1 and 3.

Conclusion: This study shows that percutaneous screw fixation procedure is the preferable minimally invasive technique in terms of minimizing muscle injury associated with L4-L5 spondylolisthesis.
\end{abstract}

Key Words: Paraspinal muscle sparing approach - Percutaneous screw fixation - Tissue injury

\section{INTRODUCTION}

Posterior lumbar interbody fusion (PLIF) is a widely performed surgical procedure for the management of pain and spinal instability resulting from spondylolisthesis ${ }^{13)}$. However, conventional PLIF by the midline approach for screw fixation requires a large skin incision and extensive dissection of paraspinal muscles, and thus, increases the risk of complications over the short and long terms ${ }^{5,9,10,17)}$.

The paraspinal muscle sparing approach and percutaneous screw fixation are known to be less invasive procedures as compared with the conventional midline approach and these

- Received: September 26, 2012 - Revised: October 22, 2012

- Accepted: November 27, 2012

Corresponding Author: Seok Won Kim, MD, PhD

Department of Neurosurgery, School of Medicine, Chosun University,

588, Seosuk-dong, Dong-gu, Gwangju-city, 501-717, Republic of Korea

Tel: +82-62- 220-3126, FAX: +82-62- 227-4575

E-mail: ns64902@hanmail.net/chosunns@chosun.ac.kr

*This study was supported by chosun university fund in 2009. techniques have been used with the goal of reducing muscle injury ${ }^{4}$. However, no comparative quantitative analysis has been performed on tissue trauma and systemic inflammatory responses after these minimally invasive techniques. Muscle injury during spine surgery increases serum concentrations of muscle-originated enzymes such as creatine kinase (CK), aldorase, Troponic C type 2 fast (TNNC2), lactate dehydrogenase, etc. Amomg them, CK-MM and TNNC2 are specific for skeletal muscle injury that rapidy release into circulation. The proinflammatory cytokine (IL-8) and anti-inflammatory cytokine (IL1ra) are also related directly to the degree of muscle injury.

The purpose of this study was to compare these minimally invasive techniques of screw fixation in terms of muscle injury and inflammatory response by quantitatively analyzing serum enzyme and inflammatory cytokine levels.

\section{MATERIALS AND METHODS}

Twenty-two patients who underwent single level PLIF for L4-L5 spondylolisthesis were included in this study. Patients 
with chronic illness, a history of malignancy or of infectious disease, or an elevated erythrocyte sedimentation rate (ESR) or C-reactive protein (CRP) level in preoperation check were excluded from this study. Those on medications or with conditions that could have interfered with results, such as, cardiovascular disease or muscular disease, which can elevate serum enzymes, were also excluded. After receiving the written consent of this study, the 22 patients were allocated to one of two groups. Group I consisted of 11 patients (three males and eight females) treated by PLIF using interbody cages by the paraspinal muscle sparing approach for screw fixation. The paramedian fascial incisions were made in their correct place, which was usually located $2-3 \mathrm{~cm}$ lateral to the midline. After the natural cleavage plane of the anatomic intermuscular space between multifidus and longissimus muscles were identified for pedicle screw placement (Fig. 1). Group II also consisted of 11 patients (three males and eight females) treated by PLIF using interbody cages by percutaneous screw fixation. Peripheral venous blood samples were collected from all patients at 6 AM the day of the surgery and at 1,3, and 7 days after the surgery. Samples were contained in a K3-EDTA-treated tube (Becton Dickinson, Ontario Canada) and two serum separation tubes (Becton Dickinson, Mississauga, Canada). Complete blood cell counts and ESR were determined using the Advia 2120 system (Siemens Healthcare Diagnostics GmbH, Eschborn, Germany) and the Test-1 analyzer (Alifax, Padova, Italy), respectively, in EDTA-treated whole blood. To separate serum, separation tubes were centrifuged immediately at 3,500 rpm for 10 minutes within one hour of blood sampling. The separated serum was stored at a $-70^{\circ} \mathrm{C}$ in a deep freezer for the four biomarker assays. The CK-MM and TNNC2 activities were determined using quantitative enzyme-linked immunosorbent assay (ELISA) kits (Uscn Life Science \& Technology Co., Beijing, China), and the serum concentrations of IL-8 (a pro-inflammatory cytokine) and IL-1ra (an anti-inflammatory cytokine) were measured using quantitative ELISA kits
(Invitrogen, Carlsbad, CA). The preoperative group differences were evaluated using the student's t-test for unpaired data. The Mann-Whitney U test in SPSS ver. 13 was used for the statistical analysis for the result. Results are presented as means and standard deviations. Statistical significance was accepted for $\mathrm{p}$ values of $<0.05$.

\section{RESULTS}

\section{Patient demographics and clinical data}

No significant intergroup difference was observed for age, gender, or type of spondylolisthesis. The mean operative time from skin incision to complete wound closure was 208.4 minutes (range, 178-230 minutes) in Group I and 151.7 minutes (range, $125-187$ minutes) in Group II ( $\mathrm{p}=0.083)$. The amounts of intraoperative blood loss and of postoperative blood transfusion and the extent of midline skin incision were also higher in Group I, though not significantly so (Table 1).

\section{Changes in creatinine kinase (CK-MM)}

Mean CK-MM concentration was significantly higher in Group I ( $500.3 \pm 44 \mathrm{ng} / \mathrm{mL}$ versus $299.4 \pm 54 \mathrm{ng} / \mathrm{mL} ; \mathrm{p}=0.014)$ on day 1 , and on day $3(384.4 \pm 31 \mathrm{IU} / \mathrm{L}$ versus $215.3 \pm 43 \mathrm{ng} /$ $\mathrm{mL} ; \mathrm{p}=0.011)$. CK-MM concentrations returned to baseline at 7 days postoperatively in both groups (Fig. 1).

\section{Changes in tropoin $C$ type 2 fast (TNNC2)}

Mean TNNC2 concentration showed a steeper increase in Group I than in Group II on day $1(413 \pm 45 \mathrm{pg} / \mathrm{mL}$ versus $287 \pm 39 \mathrm{pg} / \mathrm{mL} ; \mathrm{p}=0.005)$ and day $3(348 \pm 59 \mathrm{pg} / \mathrm{mL}$ versus $249 \pm 36 \mathrm{pg} / \mathrm{mL} ; \mathrm{p}=0.011)$. The concentrations of TNNC2 also returned to baseline at 7 days in both groups (Fig. 2).

Table 1. Patients demographics and backgrounds

\begin{tabular}{lccc}
\hline \hline & Group I & Group II & p-value \\
\hline Age (yr) & (Paraspinal approach) & (Percutaneous screw fixation) & \\
Male: Female (\%male) & $65.1 \pm 15.8$ & $63.5 \pm 18.2$ & $3: 8(27 \%)$ \\
Spondylolisthesis & $3: 8(27 \%)$ & & \\
$\quad$ Degenerative & 8 & 8 & 0.083 \\
$\quad$ Spondylolytic & 3 & 3 & 0.162 \\
Time for operation (min) & $208.4(178-230)$ & $151.7(125-187)$ & 0.172 \\
Intraoperative blood loss (mL) & $448.5(381-608)$ & $302.3(278-396)$ & 0.155 \\
Transfusion (pint) & $1.3(0-2)$ & $0.4(0-2)$ & $7.6(6.8-9.0)$ \\
Midline skin incison $(\mathrm{cm})$ & $10.0(805-12.4)$ & & \\
\hline
\end{tabular}



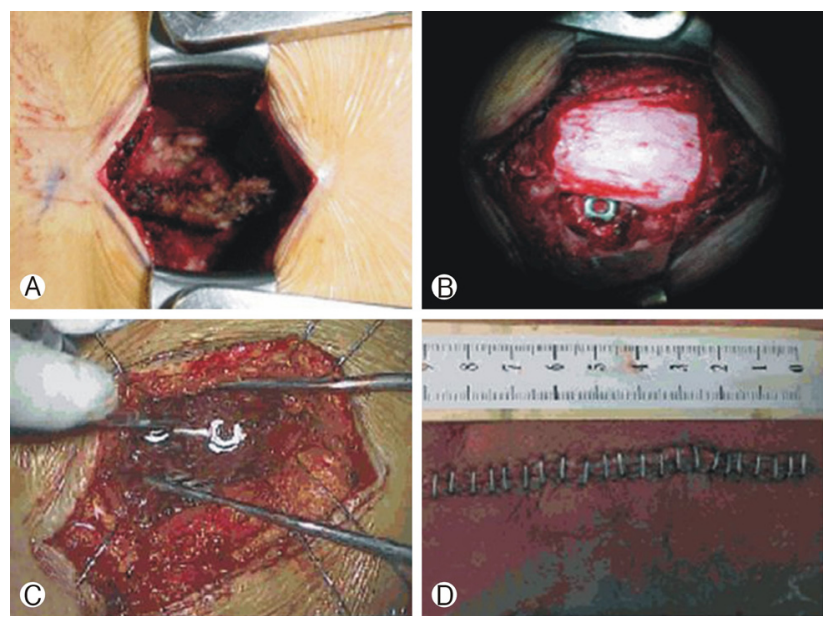

Fig. 1. Intraoperative photographs of screw fixation via paraspinal muscle sparing approach. (A) Through a midline skin incision, the spinal processes, laminae, and facet joints were exposed. (B) Following decompression and discectomy, two titanium cages are inserted into the intervertebral space. (C) Paramedian fascial incision are made in $2-3 \mathrm{~cm}$ lateral to midline and screws are inserted via the paraspinal muscle sparing approach between longissimus and multifidus muscle. (D) Postoperative skin incision shows single midline incision.

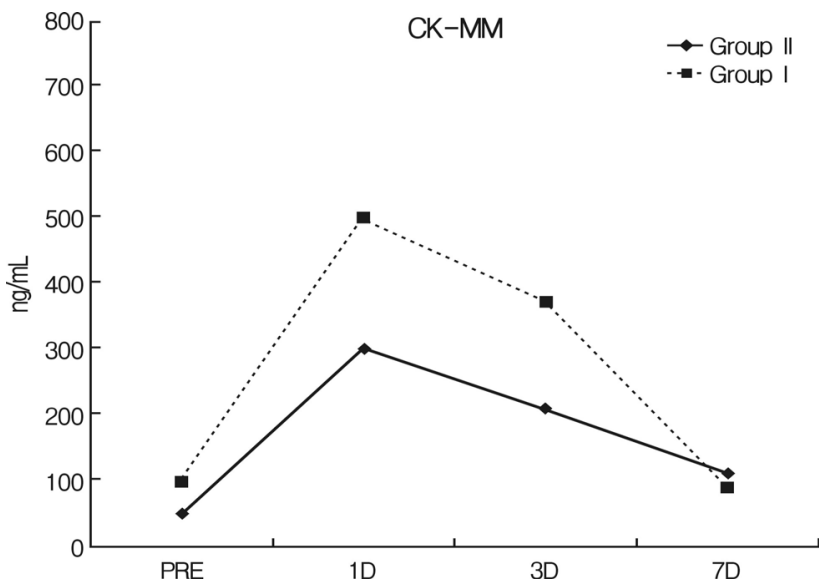

Fig. 2. Serum creatinine kinase (CK-MM) concentrations for both groups. The Group II shows lower level of CK-MM than the Group I significantly on postoperative 1 day and 3 days after surgery. The CK-MM concentrations of the both group were returned to baseline after 7 days.

\section{Changes in the serum levels of IL-8}

Although IL-8 levels increased more rapidly after surgery in Group I than in Group II, this increase was no more rapid than that observed for other cytokines in either group. Furthermore, IL-8 levels were not significantly different at any time in the two study groups (Fig. 3).

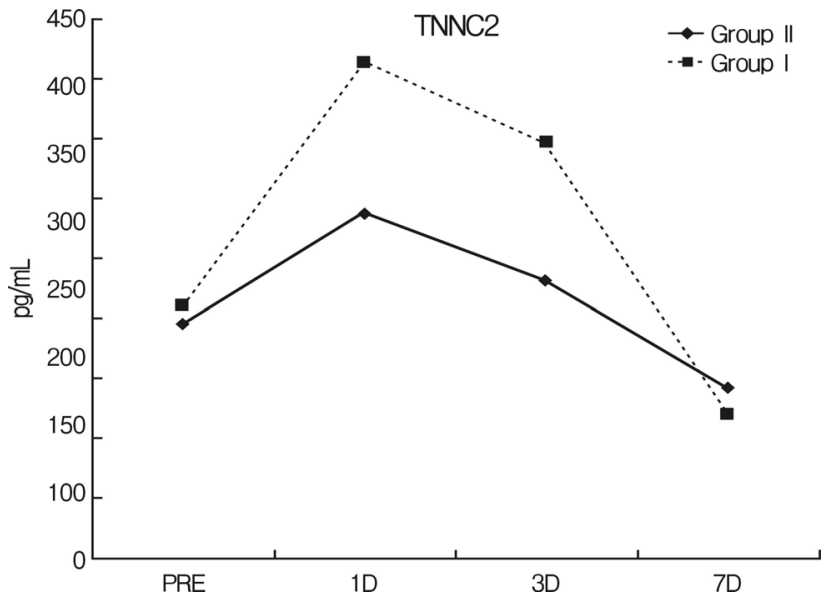

Fig. 3. Serum TNNC2 concentrations for the Group II show lower level than the Group I significantly on postoperative 1 day and 3 days $(p<0.05)$. They returned to baseline after 7 days.

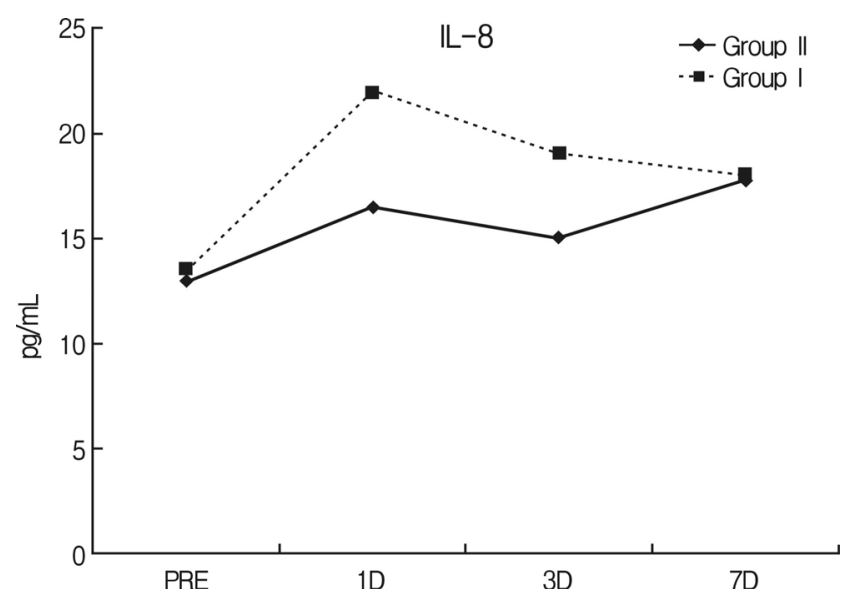

Fig. 4. Serum IL-8 concentrations. Although IL-8 level increased more rapidly in Group I than in Group II, it was not significantly different at any time.

\section{Changes in the serum levels of IL-1ra}

IL-1ra concentrations were significantly higher in Group I than in Group II on day $1(1,230 \pm 1842 \mathrm{pg} / \mathrm{mL}$ versus $785 \pm$ $103 \mathrm{pg} / \mathrm{mL}$, respectively; $\mathrm{p}=0.001)$ and day $3(824 \pm 107 \mathrm{pg} /$ $\mathrm{mL}$ versus $530 \pm 97 \mathrm{pg} / \mathrm{mL}$, respectively; $\mathrm{p}=0.002)$. Concentrations in both groups returned to baseline on day 7 (Fig. 4).

\section{DISCUSSION}

Traditional procedures for symptomatic spondylolisthesis involve spinal decompression and fusion with supplemental instrumentation ${ }^{6}$. However, the traditional implantation of spinal instrumentation by midline approach requires extensive 


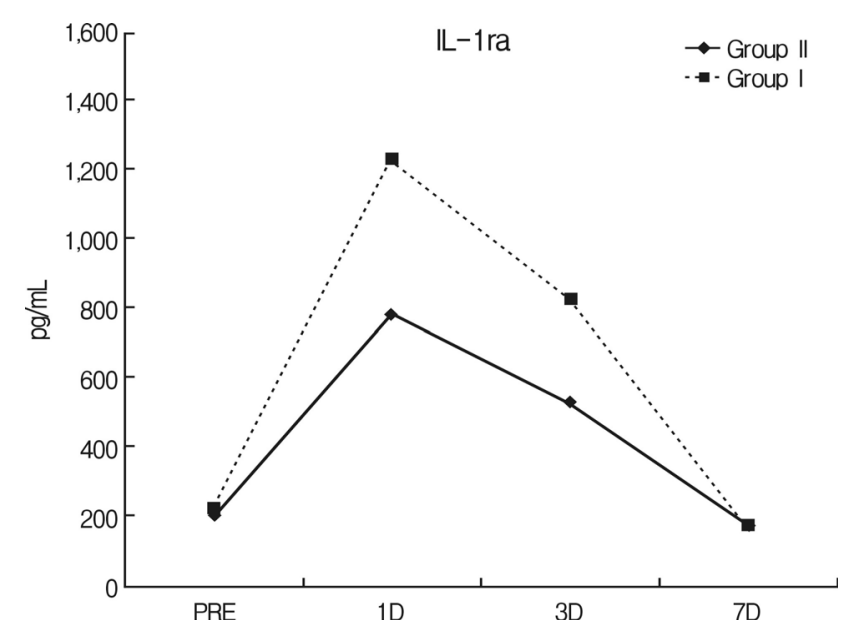

Fig. 5. The mean serum IL-1 ra concentration for the study group was significantly lower than the control group, on postoperative 1 day and 3 days.

tissue dissection to expose entry points and provide the required lateral-to-medial orientation for optimal screw trajectory ${ }^{8)}$. As a result, excessive dissection may result in the denervation of muscles and facet capsules, proximal facet joint damage, and the weakening of other supportive structures, and cause prolonged postoperative pain and functional disability ${ }^{1,11)}$.

In contrast, minimally invasive percutaneous screw fixation and screw fixation via the paraspinal muscle sparing approach are more desirable because they cause less muscle damage than the traditional midline approach, and have positive effects on postoperative trunk muscle performance ${ }^{3,6)}$.

The previous clinical reports on minimally invasive techniques have included various clinical parameters, such as, the visual analogue pain scale, operative time, intraoperative and postoperative blood loss, and overall clinical results ${ }^{4,5)}$. Kim et $\mathrm{al}^{11)}$. also reported mini-open PLIF had less tissue injury and less systemic response than the conventional PLIF by midline approach. However, no previous report has compared these less invasive techniques quantitatively using the serum levels of inflammatory markers of invasiveness. It is known that muscle injury during spine surgery is directly associated with retraction time and the external compression force exerted by the retractor.

In the present study, percutaneous screw fixation caused smaller increases in the serum levels of inflammatory mediators and muscle enzymes. Mean operative time was shorter and estimated blood loss was lower in Group II (percutaneous screw fixation group) although differences were not significant. In the kit, anti-CKM antibody binds specifically to the human CK-MM isoform, which is a creatine phosphokinase predominantly found in skeletal muscles. On the other hand, TNNC2 is a fast skeletal troponin $\mathrm{C}$ isoform that is expressed in fast-twitch skeletal muscles. In contrast, the slow troponin $\mathrm{C}$ isoform (TNNC1) is expressed in heart muscle and slowtwitch skeletal muscles, and thus, CK-MM and TNNC2 have been used as markers of skeletal injury ${ }^{14-16}$. In the present study, levels of muscle enzymes in both groups were found to be significantly different. Both CK-MM and TNNC2 levels were significantly increased on day 1 and 3 , and returned to baseline on day 7 .

Any type of injury, including major surgery, can cause massive systemic inflammation with clinical manifestations. Macro phages initially induce interleukins (IL)- 1 and tumor necrosis factor (TNF)-alpha in reaction to surgical stress. Although these cytokines are not detectable in peripheral blood following the surgery because of their small amounts or rapid decomposition, these pro-inflammatory cytokines are believed to induce the productions of IL- 6 and IL- $8^{11}$. In particular, IL-8 (a proapoptotic cytokine) is produced by endothelial cells, and is responsible not only for the accumulation of neutrophils at sites of inflammation but is also for chemotaxis attracting basophils and lymphocytes to sites of initial systemic inflammatory reactions. However, in this study, the serum IL-8 levels were non-significantly different in the groups, though higher in Group I. The difference between peak IL-8 concentrations on day 1 was not as great as differences between other markers, possibly because time to peak concentrations differed. It has been reported that the concentrations of other cytokines peak on day 1 , whereas IL-8 concentrations peak on the day of spinal the surgery ${ }^{7}$.

Anti-inflammatory cytokine and pro-inflammatory cytokine inhibitors induce compensatory reactions by controlling or down regulating proinflammatory cytokines. IL-1ra is an inhibitor of IL-1 and occupies the cell surface receptor of IL-1 and its serum level is considered a more reliable marker of than IL-1 itself $^{2}$. In the present study, the difference between IL-1ra levels in the two groups remained significant until day 3. This is consistent with the findings of previous studies, which found that compensatory response is as extensive as initial inflammatory response in terms of achieving a balance between pro- and anti-inflammatory responses and restoring immunologic homeostasis ${ }^{12)}$.

In this study, we included single-level lumbar interbody fusion cases for L4-L5 spondylolisthesis only and excluded patients with chronic medical diseases. Although no clinical complication was encountered, statistically meaningful intergroup differences were found for all except IL-8. As a result, our results indicate that systemic inflammatory reactions are more severe for screw fixation via the paraspinal muscle sparing approach as compared with percutaneous screw fixation. Despite its prospective nature, the present study had a small patient group, and thus, we suggest that further larger-scale investigations 
involving more rigorous patients and the selection of more markers should be undertaken.

\section{CONCLUSION}

Although both screw fixation via the paraspinal muscle sparing approach and percutaneous screw fixation are known to be satisfactory techniques that cause less muscle injury than the conventional midline approach, the present study shows that percutaneous screw fixation may significantly reduce systemic inflammatory response as compared with the paraspinal muscle sparing approach during the acute postoperative period.

\section{REFERENCES}

1. Apple FS, Hellsten Y, Clarkson PM: Early detection of skeletal muscle injury by assay of creatine kinase $\mathrm{mm}$ isoforms in serum after acute exercise. Clin Chem 34(6):1102-1104, 1988

2. Choi SK, Lee GJ, Choi S, Kim YJ, Park HK, Park BJ: Neuroprotective effects by nimodipine treatment in the experimental global ischemic rat model: Real time estimation of glutamate. J Korean neurosurg Soc 49(1):1-7, 2011

3. Datta G, Gnanalingham KK, Peterson D, Mendoza N, O'Neill K, Van Dellen J, et al: Back pain and disability after lumbar laminectomy: is there a relationship to muscle retraction? Neurosurgery 54(6):1413-1420, 2004

4. Gahlmann R, Kedes L: Cloning, structural analysis, and expression of the human fast twitch skeletal muscle troponin $\mathrm{c}$ gene. J Biol Chem 265:12520-12528, 1990

5. Gahlmann R, Wade R, Gunning P, Kedes L: Differential expression of slow and fast skeletal muscle troponin c. slow skeletal muscle troponin $\mathrm{c}$ is expressed in human fibroblasts. J Mol Biol 201(2):379-391, 1988

6. Granowitz EV, Santos AA, Poutsiaka DD, Cannon JG, Wilmore DW, Wolff SM, et al: Production of interleukin-1-receptor antagonist during experimental endotoxaemia. Lancet 338(8780):
1423-1424, 1991

7. Hyun SJ, Kim YB, Kim YS, Park SW, Nam TK, Hong HJ, et al: Postoperative changes in paraspinal muscle volume: comparison between paramedian interfascial and midline approaches for lumbar fusion. J Korean Med Sci 22(4):646-651, 2007

8. Jang KS, Kim HS, Ju CI, Kim SW, Lee SM, Shin H: Paraspinal muscle sparing versus percutaneous screw fixation: a prospective and comparative study for the treatment of L5-S1 spondylolisthesis. J Korean Neurosurg Soc 49(3):163-166, 2011

9. Kawaguchi Y, Matsui H, Tsuji H: Back muscle injury after posterior lumbar spine surgery. a histologic and enzymatic analysis. Spine (Phila Pa 1976) 21(8):941-944, 1996

10. Kim HS, Park IH, Ryu JK, Kim SW: Bone cement augmentation of pedicular screwing in sever osteoprotic spondylolisthetic patients. J Korean Neurosurg Soc 42:6-10, 2007

11. Kim KT, Lee SH, Suk KS, Bae SC: The quantitative analysis of tissue injury markers after mini-open lumbar fusion. Spine (Phila Pa 1976) 31(6):712-716, 2006

12. Lee SH, Choi WG, Lim SR, Kang HY, Shin SW: Minimally invasive anterior lumbar interbody fusion followed by percutaneous pedicle screw fixation for isthmic spondylolisthesis. Spine J 4(6):644-649, 2004

13. Lim TK, Lee SG, Park CW, Kim WK, Son S, LEE K: Comparative analysis of adjacent levels of degeneration and clinical outcomes between conventional pedicle screws and percutaneous pedicle screws in treatment of degenerative disease at L3-5; a preliminary report. Korean J Spine 9(2):66-73, 2012

14. Lowery GL, Kulkarni SS: Posterior percutaneous spine instrumentation. Eur Spine J (Suppl 1) 9:S126-130, 2000

15. Suwa H, Hanakita J, Ohshita N, Gotoh K, Matsuoka N, Morizane A: Postoperative changes in paraspinal muscle thickness after various lumbar back surgery procedures. Neurol Med Chir (Tokyo) 40(3):151-154, 2000

16. Takahashi J, Ebara S, Kamimura M, Kinoshita T, Misawa H, Shimogata M, et al: Pro-inflammatory and anti-inflammatory cytokine increases after spinal instrumentation surgery. J Spinal Disord Tech 15(4):294-300, 2002

17. Wetzel FT, LaRocca H: The failed posterior lumbar interbody fusion. Spine (Phila Pa 1976) 16(7):839-845, 1991 